\title{
Correction to: Preclinical pharmacological in vitro investigations on low chloride conductance myotonia: effects of potassium regulation
}

\author{
Kerstin Hoppe $^{1,2}$ D $\cdot$ Sunisa Chaiklieng ${ }^{3,4} \cdot$ Frank Lehmann-Horn $^{2} \cdot$ Karin Jurkat-Rott $^{5} \cdot$ Scott Wearing $^{6,8}$. \\ Werner Klingler ${ }^{6,7,8}$
}

Published online: 3 September 2020

(C) Springer-Verlag GmbH Germany, part of Springer Nature 2020

\section{Correction to: Pflügers Archiv - European Journal of Physiology (2020) https://doi.org/10.1007/s00424-020-02410-4}

The original article contains an error during online publication. Table 2 was included during production round and now deleted. The Original article has been corrected.

Publisher's note Springer Nature remains neutral with regard to jurisdictional claims in published maps and institutional affiliations.

The online version of the original article can be found at https://doi.org/ 10.1007/s00424-020-02410-4

Kerstin Hoppe

Hoppekerstinmed@t-online.de

1 Department of Anesthesiology, Intensive Care Medicine and Pain Therapy, University Hospital Frankfurt, Goethe University Frankfurt, Theodor-Stern-Kai 7, 60590 Frankfurt, Germany

2 Department of Anesthesiology, Intensive Care Medicine and Pain Therapy, University Hospital of Wuerzburg, Oberduerrbacher Str. 6, 97080 Wuerzburg, Germany

3 Division of Neurophysiology in the Center of Rare Diseases, Ulm University, Albert Einstein Allee 23, 89081 Ulm, Germany

4 Faculty of Public Health, Khon Kaen University, Muang Khon Kaen, Thailand
5 Division of Experimental, Universtiy Medical Center Ulm, Anesthesiology, Albert-Einstein-Allee 23, 89081 Ullm, Germany

6 Institute of Health and Biomedical Innovation, Queensland University of Technology, 60 Musk Avenue, Kelvin Grove 4059, Australia

7 Department of Anesthesiology, Intensive Care Medicine and Pain Therapy, SRH Clinincs, Hohenzollernstraße 40, 72488 Sigmaringen, Germany

8 Department of Conservative and Rehabilitation Orthopedics, Faculty of Sport and Health Science, Technical University of Munich, Gerog-Brauchle-Ring 60/62, Munich, Germany 